\title{
SIMULATION OF MATERIAL FLOW THROUGH A SAMPLE DIVIDER
}

\author{
Jiri Rozbroj', Jan Necas ${ }^{1 *}$, David Zurovec ${ }^{1}$, Jakub Hlosta ${ }^{1}$, Daniel Gelnar ${ }^{1}$, Jiri Zegzulka ${ }^{1}$ \\ 1 VSB-Technical University of Ostrava, ENET Centre, 17. listopadu 15/2172, 70833 Ostrava-Poruba, Czech \\ Republic \\ * Corresponding author's e-mail: jan.necas@vsb.cz
}

Received: 2018.01.15

Accepted: 2018.02.01

Published: 2018.03.01

\begin{abstract}
The prerequisite for a modern approach to innovative procedures of the development of current or even newly created equipment for the transport of particulate materials is the utilization of simulation methods, such as the Discrete Element Method (DEM). This article focuses on the basic, or initial, validation of movement of material through the sample divider. The mechanical-physical properties of brown coal were measured. Based on these parameters the preliminary input values for EDEM Academic were selected, and a simulation of the dividing process was run. The key monitored parameters included density and friction coefficient. Experiments on a realistic model of the equipment were performed and assessed. The total weights of brown coal at the exit from the divider were determined for a specific speed of the divider. The aim of this task was to simulate the realistically determined weight division of the brown coal sample. The result from the DEM was compared with the results of measurement on a realistic model.
\end{abstract}

Keywords: discrete element method, sampling divider, validation, coal

\section{INTRODUCTION}

In coal mines and incineration plants it is necessary to have an overview and records of coal quality $[1,2,3]$. The aim is to maintain and check high quality of coal at stable favourable prices even with respect to the environment [4]. Samples are usually taken directly from the transport route [5] even several times per shift. Theses samples are further checked in accredited laboratories. The sampling equipment and systems play an important role here. Innovation in the field of sampling equipment involves automation of the sampling operation. To implement this automation, it is necessary to know all the possible operating modes of the sampling equipment. In the field of studying processes and investigating operating modes of transport equipment, which work with particulate materials, the use of the Discrete Element Method (DEM) [6, 7, 8, 9] presents itself. The input parameters for the DEM are mechanical-physical properties, which best describe a specific particulate material. Typically, these include grain size, material density, friction between particles and contact geometry $[10,11]$.

The DEM can be used for the analysis and study of processes occurring inside the equipment, where one cannot see with, for example, an optical device to record video and collect data [12]. This can be used to find critical passive areas of material flow, or other undesirable and inefficient modes of the equipment [13].

However, to vindicate the quality or correctness of the simulation it is still necessary to perform measurements. Important aspects include transport outputs of equipment, weight emptying of equipment in time, possible dynamic or mechanical loading and material properties $[14,15$, $16,17,18,19,20,21,22]$. The use of the DEM alone does not necessarily have the correct predicative value without previous knowledge from measurements on investigated equipment. Cali- 
bration and validation of the equipment's DEM model is important and this is not objective without measurement on realistic equipment [23, 24].

In this article, validation of DEM simulation is performed using measurement of the weight increase in time on realistic equipment. Material exits the equipment through two outlets. One outlet is the sampling outlet and is used for the collection of material for laboratory analyses. The second outlet is the waste outlet, which returns residue material from the sample divider back to the transport route. Experimentally determined weight parameters at equipment outlets in time were compared with DEM simulation.

\section{METHODS AND EXPERIMENTS}

Experiments were performed on a realistic sample divider model. The overall outside diameter of the equipment is $0.86 \mathrm{~m}$ and the height is $0.75 \mathrm{~m}$. There are three main functional parts. The first and top part is the inlet part. Here, material enters onto the blade wheel, which evenly distributes the input material. From this space with the blade wheel with one opening, which is static in relation to the blade wheel, the material travels to the centre (second) section. Here there is a rotational disc, which is connected by a shaft to the blade wheel at the entry into the equipment. This rotating disc has symmetrically located holes, which rotate together with the disc. The material falls through the rotating holes in the disc either into the outlet for sampling or into the third bot- tom section. This part also contains a blade wheel which ensures regular output of material from the equipment back to the transport route. This blade wheel is also connected by a shaft with the blade wheel at the equipment inlet. The outlet from the equipment for sampling is located directly under the static opening of the first part. A disc with openings rotates between the static opening and the outlet for sampling. At the moment when the opening of the rotating disc between the equipment outlet for sampling and the static opening of the first part coincide, material falls from the first part into the sampling outlet, and a sample is taken. The experimental equipment is shown in Figure 1 and the 3D model in Figure 2.

During experiments the speed of the sampling equipment was set to $29 \mathrm{rpm}$. A total of $10 \mathrm{~kg}$ of brown coal was fed into the equipment continually. The filling process took $40 \mathrm{~s}$. This corresponds to a fed quantity of $0.25 \mathrm{~kg} \cdot \mathrm{s}-1$. Filling of the sampling equipment was provided by a controlled belt conveyor. At both outlets from the sampling equipment the quantity of material in $\mathrm{kg}$ was detected, which changed in time. Detection of the weight was performed using strain gauge scales, which were connected to a laptop via a DS-NET measuring card.

The $3 \mathrm{D}$ model of the sampling equipment was created according to the dimensions of the realistic experimental equipment using CAD software. This model was imported into the EDEM Academic simulation program in *.STL format. The parameters used for material geometry and particles are shown in Table 1 and Table 2. Simulation
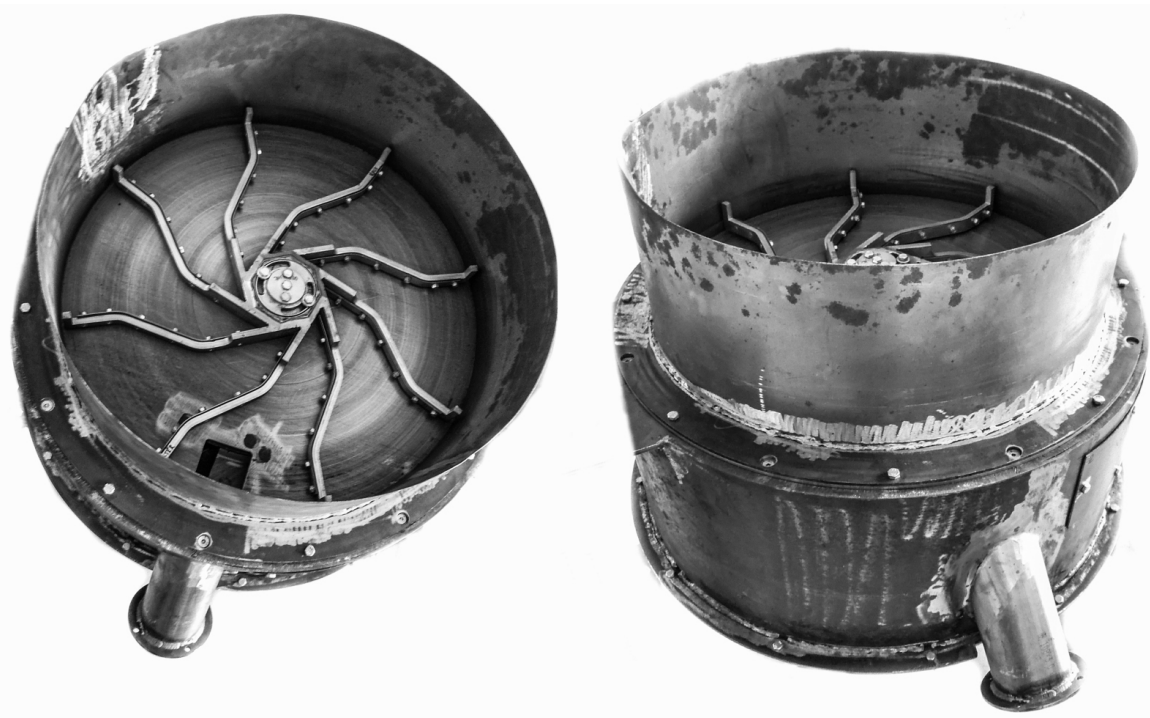

Fig. 1.. Experimental sampling equipment 


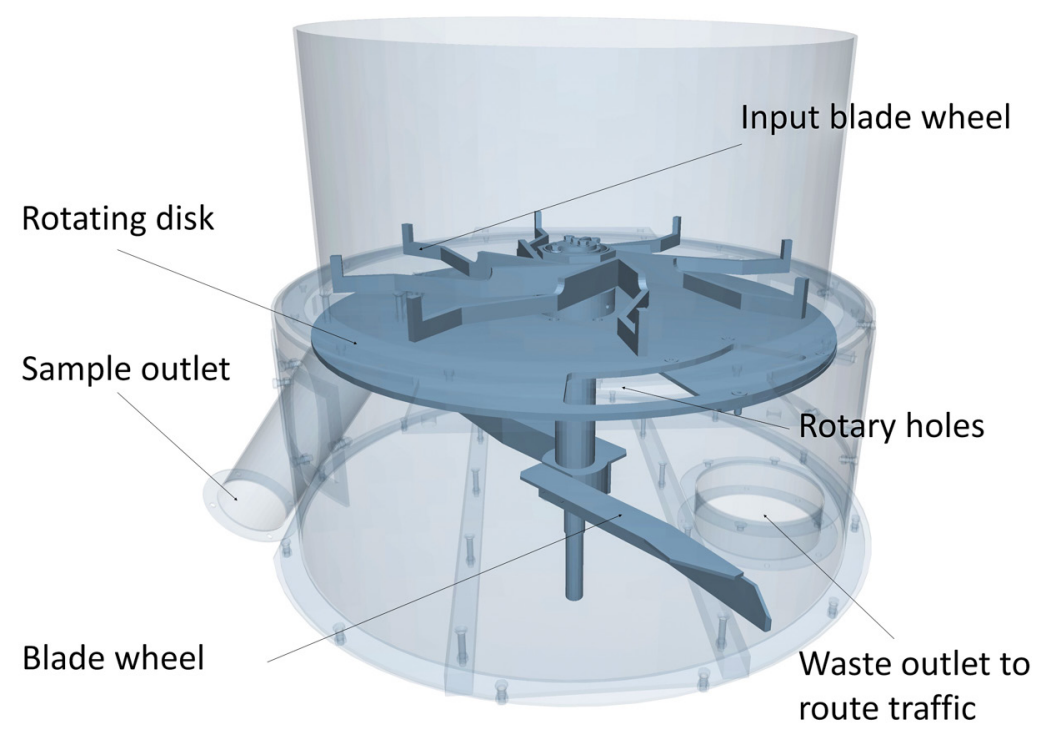

Fig. 2. 3D model of sampling equipment

experiments were performed using a $3 \mathrm{~mm}$ particle diameter. The particle density was determined experimentally using EDEM Academic. This was based on the realistic experiment, where a cylinder $(0.1185 \mathrm{~m}$ diameter and $0.197 \mathrm{~m}$ height $)$ was filled with a sample of coal and weighed. This experiment was repeated several times and an average sample weight of $1.712 \pm 0.013 \mathrm{~kg}$ was determined for a volume of $0.0022 \mathrm{~m} 3$. The same cylinder was filled in the DEM and the material particle density was changed so as to achieve the required level height in the measuring cylinder, while maintaining a total sample weight of 1.712 $\mathrm{kg}$. The shear modulus of particles was selected at a minimum value with respect to the calculation time of the simulation. The coefficient of static friction for the particles was selected based on measurement of the effective angle of internal friction of a coal sample using the RST-01 shear

Table 1. Material properties

\begin{tabular}{|l|l|l|}
\hline Input parameter & Geometry & Particle \\
\hline Poisson's Ratio $(-)$ & 0.3 & 0.25 \\
\hline Shear Modulus $(\mathrm{Pa})$ & $8.077 \mathrm{e}+10$ & $1 \mathrm{e}+06$ \\
\hline Density $\left(\mathrm{kg} \cdot \mathrm{m}^{-3}\right)$ & 7800 & 1650 \\
\hline
\end{tabular}

Table 2. Contacts parameters

\begin{tabular}{|l|l|l|}
\hline Input parameter & $\begin{array}{l}\text { Geometry- } \\
\text { Particle }\end{array}$ & $\begin{array}{l}\text { Particle- } \\
\text { Particle }\end{array}$ \\
\hline Coefficient of Restitution (-) & 0.5 & 0.4 \\
\hline Coefficient of Static Friction (-) & 0.32 & 1 \\
\hline Coefficient of Rolling Friction (-) & 0.1 & 0.01 \\
\hline
\end{tabular}

machine. The coefficient of static friction between particles and the geometry were selected based on measurements made on the Jenike shear machine.

The profile of weight curves in time from both sampling equipment outlets in the DEM simulation was obtained using the Selections-Geometry Bin function (Figure 3). These selections detect the increase in particle weight in time. These values were exported to tables and graphs were plotted. The outputs from the realistic experiment were processed using DEWESoft 7.0 software. Weight values in $5 \mathrm{~s}$ time intervals were selected to consolidate and compare outputs from the DEM and DEWESoft.

\section{RESULTS AND DISCUSSION}

Firstly, experiments were performed on the realistic equipment. Ten experiments of filling and emptying were performed on the sampling equipment. Figure 4 shows a record of ten measurements together with the average value at the waste outlet from the sampling equipment. Figure 5 shows a record of ten measurements at the sampling outlet together with the average value.

The average weight value from the realistic experiment at the waste outlet was $8.68 \pm 0.05 \mathrm{~kg}$ and $1.18 \pm 0.02 \mathrm{~kg}$ at the sampling outlet. During one experiment an average of $9.86 \mathrm{~kg}$ coal passed through the equipment. The difference from the ten kilograms at the inlet is $0.14 \mathrm{~kg}$ on average. This value can partially be considered an error of the strain gauge scales. Furthermore, each time 


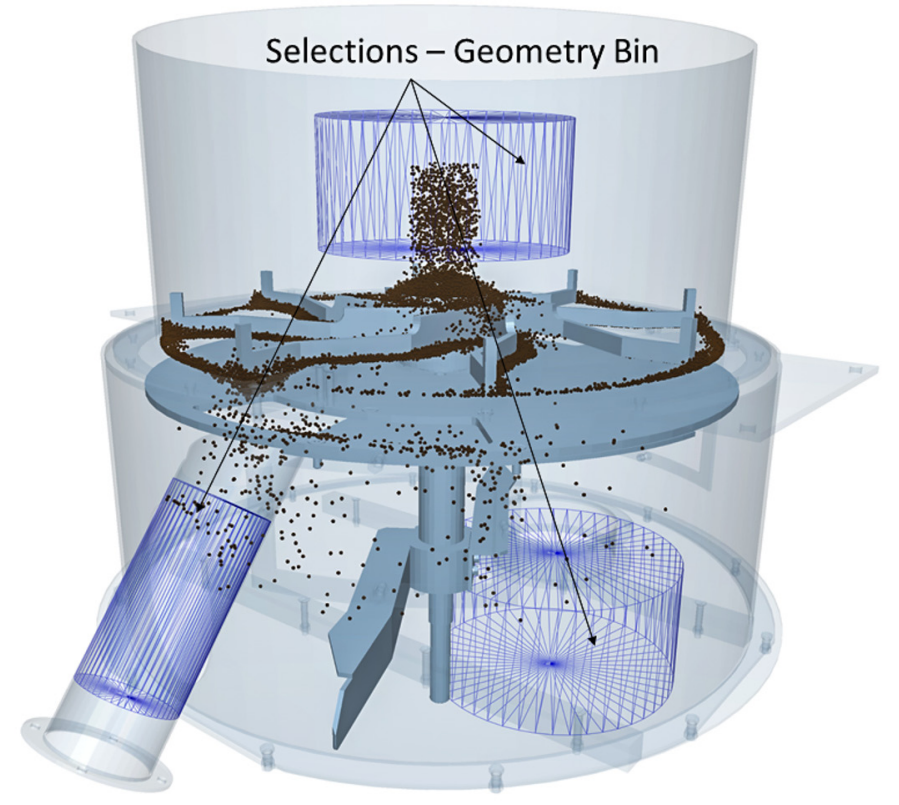

Fig. 3.. DEM model of sampling equipment with Selections-Geometry Bin

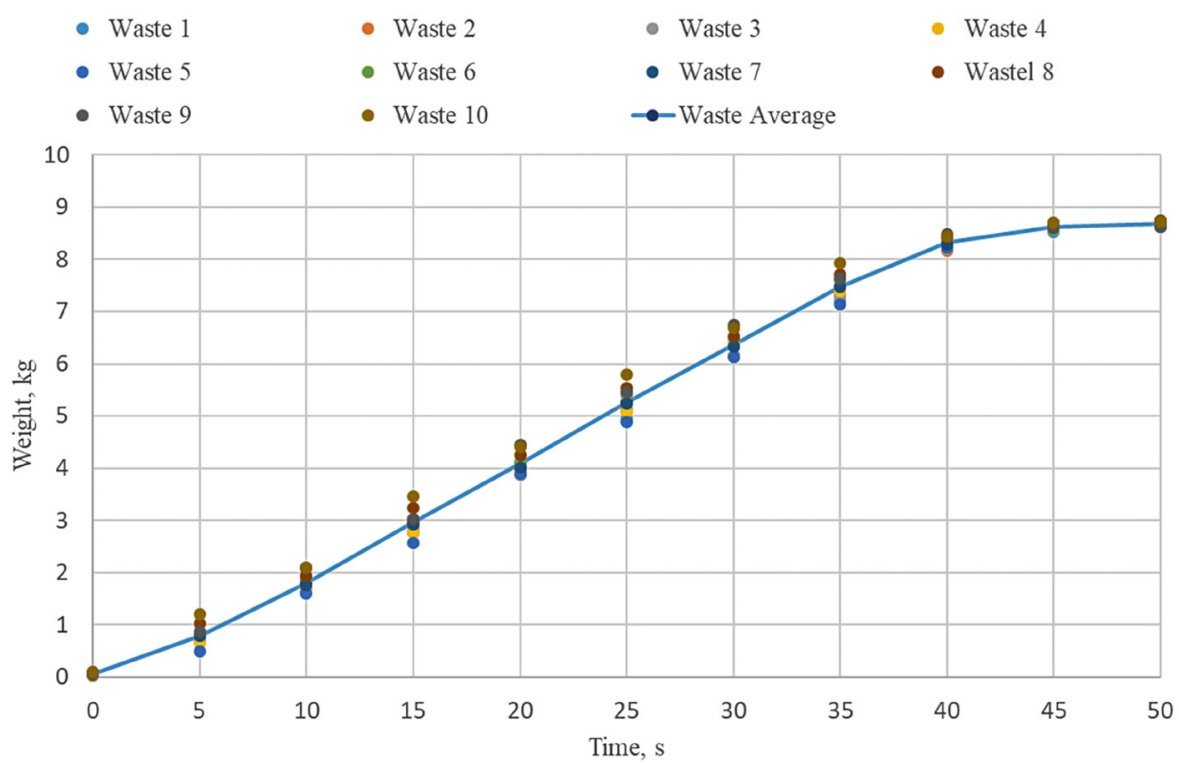

Fig. 4. Result from ten experimental measurements of weight at the waste outlet from the equipment

a different quantity of material remained in the equipment, part of the fine fraction dusted off, or settled on the equipment's internal parts.

Figure 6 shows a comparison of the realistic experiment and DEM simulation. The weight of the material at the waste outlet of the dividing equipment in the DEM simulation was $8.13 \mathrm{~kg}$. The weight of material at the sampling outlet in the simulation was $1.58 \mathrm{~kg}$. It is evident that the measured values differ between the simulation and realistic experiment. More measurements were performed in the realistic experiments. Be- sides the set of ten measurements in Figures 4 and 5 , a starting measurement was also performed. The conduct of this measurement is more similar to the DEM simulation. Prior to measurement the sampling equipment was emptied and cleaned. There was no residual material in the equipment from previous measurements. A weight of $7.89 \mathrm{~kg}$ was measured at the waste outlet and $1.02 \mathrm{~kg}$ at the sampling outlet of the sampling equipment. Theoretically, $1.09 \mathrm{~kg}$ remained in equipment. These values differ more compared to the simulation than in the case of average values from 


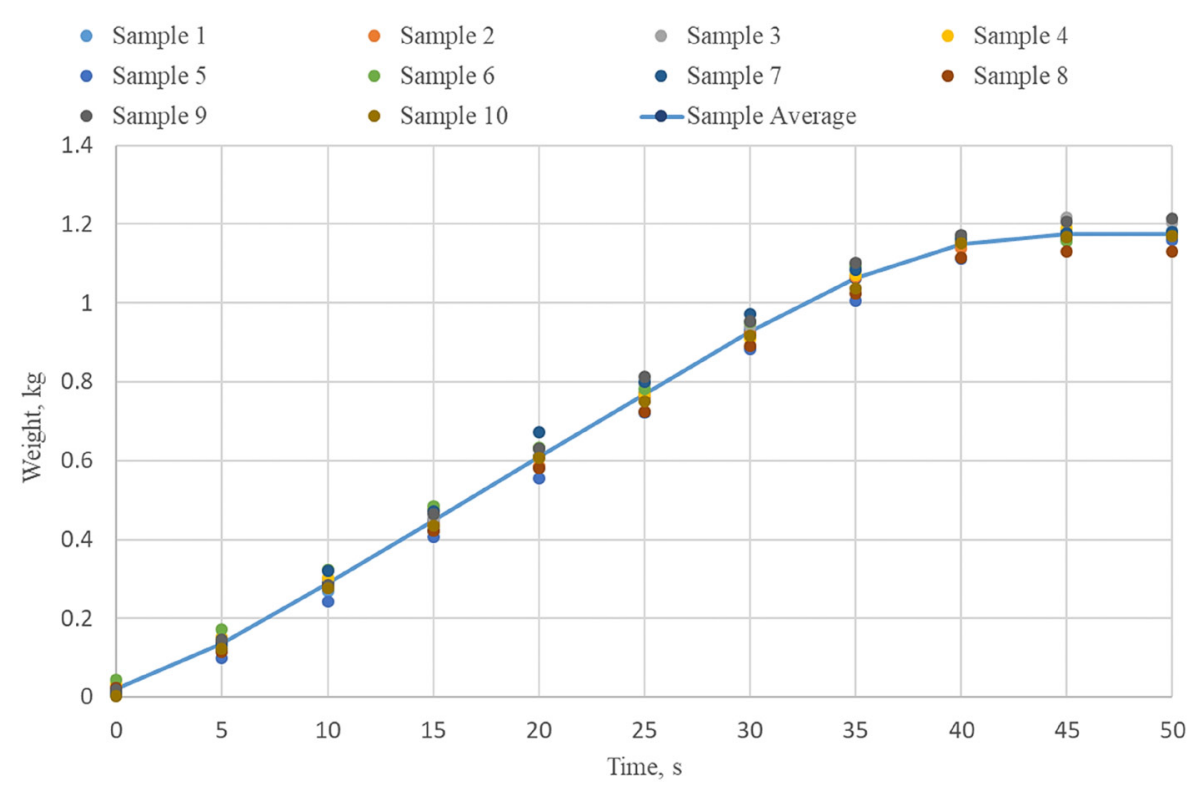

Fig. 5. Result from ten experimental measurements of weight at the sampling outlet from the equipment

ten measurements. The differences in comparing results from simulations and realistic experiments may be the result of the differences in the realistic experiment model and ideal 3D model. The 3D model does not contain all the geometric differences such as, for example, clearances or asymmetric arrangement of individual parts. The achieved results for these first validation experiments on the sampling equipment can be considered positive. Based on these results we can continue to optimize the 3D model and calibration of DEM simulation.

\section{CONCLUSIONS}

This task focused on the first testing validation of flow of material through the sample divider. Experimentally determined input parameters were used for the EDEM Academic application, such as density and friction parameters. The achieved results will be used primarily for further detailing of the simulation and calibration. Calibration will also be necessary for other modes besides just setting the $29 \mathrm{rpm}$ speed. Validation can be improved by modification of material density,

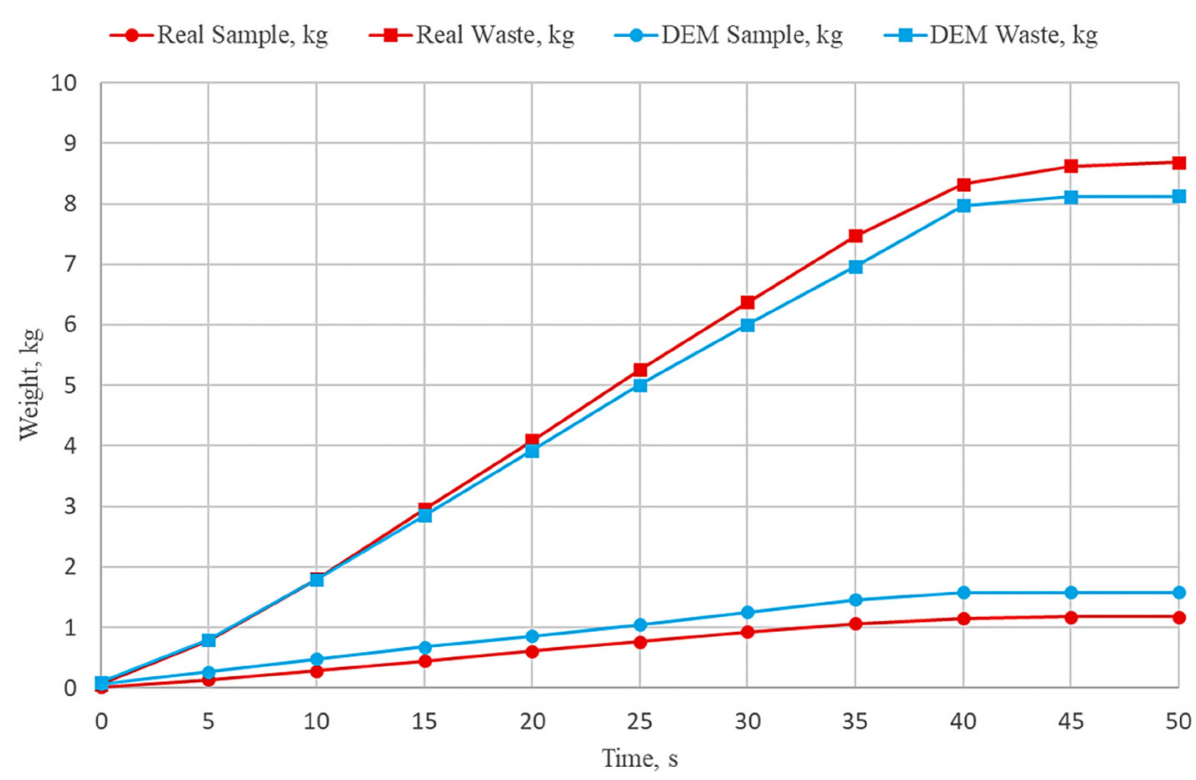

Fig. 6. Comparison of realistic experiment and DEM simulation 
particle moisture, change in speed, and others. Furthermore, attention must be paid to the possible differences between the realistic and 3D model of the sampling equipment. This task will be part of further research and study of impacts on the resultant validation of the sampling equipment.

\section{Acknowledgements}

This paper was conducted within the framework of the project LO1404: Sustainable development of ENET Centre.

\section{REFERENCES}

1. Freidina E. V., Botvinnik A. A. and Dvornikova A. N. Basic principles of coal classification by useful quality. Journal of Mining Science, 47(5), 2011, 593-605.

2. Freidina E. V., Botvinnik A. A. and Dvornikova A. N. Coal quality control in the context of international standards ISO 9000-2000. Journal of mining science, 44(6), 2008, 585-599.

3. Yang X. and Teng F. The air quality co-benefit of coal control strategy in China. Resources, Conservation and Recycling, 129, 2016, 373-382.

4. Sun D., Fang J. and SUN J. Health-related benefits of air quality improvement from coal control in China: Evidence from the Jing-Jin-Ji region. Resources, Conservation and Recycling, 129, 2018, 416-423.

5. Zhu Q. Coal sampling and analysis standards. IEA Clean Coal Centre, London, United Kingdom, 2014.

6. Owen P. J. and Cleary P. W. Prediction of screw conveyor performance using the Discrete Element Method (DEM). Powder Technology, 193(3), 2009, 274-288.

7. Guo Y., Wang S., Hu K. and Li D. Optimization and experimental study of transport section lateral pressure of pipe belt conveyor. Advanced Powder Technology, 27(4), 2016, 1318-1324.

8. Orefice L. and Khinast J. G. DEM study of granular transport in partially filled horizontal screw conveyors. Powder Technology, 305, 2017, 347-356.

9. Ramírez-Aragón C., Alba-Elías F., GonzálezMarcos A. and Ordieres-Meré J. Segregation in the tank of a rotary tablet press machine using experimental and discrete element methods. Powder Technology, 328, 2018, 452-469.

10. Syed Z., Tekeste M. and White D. A coupled sliding and rolling friction model for DEM calibration. Journal of Terramechanics, 72, 2017, 9-20.

11. Horabik J. and Molenda M. Parameters and contact models for DEM simulations of agricultural granular materials: A review. Biosystems Engineering, 147, 2016, 206-225.
12. Liu X., Hu Z., Wu W., Zhan J., Herz F., Specht E. DEM study on the surface mixing and whole mixing of granular materials in rotary drums. Powder Technology, 315 ,2017, 438-444.

13. Zhu H. P., Yu A. B. and Wu Y. H. Numerical investigation of steady and unsteady state hopper flows. Powder Technology, 170(3), 2006, 125-134.

14. Calderón C. A., Olivares M. C. V., Uñac R. O. and Vidales A. M. Correlations between flow rate parameters and the shape of the grains in a silo discharge. Powder Technology, 320, 2017, 43-50.

15. Mondal D. and Ghosh N. Study on filling factor of short length screw conveyor with flood-feeding condition. Materials Today: Proceedings, 5(1), 2018, 1286-1291.

16. Fedorko G., Molnar V., Grincova A., Dovica M., Toth T., Husakova N., Taraba V. and Kelemen M. Failure analysis of irreversible changes in the construction of rubber-textile conveyor belt damaged by sharp-edge material impact. Engineering Failure Analysis, 39, 2014, 135-148.

17. Molnar V., Fedorko G., Stehlikova B., Michalik P. and Weiszer M. A regression model for prediction of pipe conveyor belt contact forces on idler rolls. Measurement, 46(10), 2013, 3910-3917.

18. Fedorko G., Molnar V., Dovica M., Toth T. and Kopas M. Analysis of pipe conveyor belt damaged by thermal wear. Engineering Failure Analysis, 45, 2014, 41-48.

19. Molnar V., Fedorko G., Stehlikova B. and Paulikova A. Influence of tension force asymmetry on distribution of contact forces among the conveyor belt and idler rolls in pipe conveyor during transport of particulate solids. Measurement, 63, 2015, 120-127.

20. Klepka T., Dębski H. and Rydarowski H. Characteristics of high-density polyethylene and its properties simulation with use of finite element method. Polimery, 54(9), 2009, 668-672.

21. Fedorko G., Molnar V., Dovica M., Husakova N., Kral J. jr. and Ferdynus M. The use of industrial metrotomography in the field of maintenance and reliability of rubber-textile conveyor belts in closed continuous transport systems. Eksploatacja I Niezawodnosc - Maintenance and Reliability, 18(4), 2016, 539-543.

22. Jachowicz T. and Sikora R. Methods of forecasting of the changes of polymeric products properties. Polimery, 51(3), 2006, 177-185.

23. Rackl M., Top F., Molhoek C. P. and Schott D. L. Feeding system for wood chips: A DEM study to improve equipment performance. Biomass and Bioenergy, 98, 2017, 43-52.

24. González-Montellano C., Ramirez A., Gallego E. and Ayuga F. Validation and experimental calibration of 3D discrete element models for the simulation of the discharge flow in silos. Chemical Engineering Science, 66(21), 2011, 5116-5126. 